\title{
The Impact of Bankruptcy Rules on Risky Project Choice and Skill Formation under Credit Rationing
}

\author{
Gangopadhyay, Shubhashis; Wihlborg, Clas
}

Document Version

Final published version

Publication date:

2001

License

CC BY-NC-ND

Citation for published version (APA):

Gangopadhyay, S., \& Wihlborg, C. (2001). The Impact of Bankruptcy Rules on Risky Project Choice and Skill Formation under Credit Rationing. Institut for Finansiering, Copenhagen Business School. Working Papers /

Department of Finance. Copenhagen Business School No. 2001-5

Link to publication in CBS Research Portal

\footnotetext{
General rights

Copyright and moral rights for the publications made accessible in the public portal are retained by the authors and/or other copyright owners and it is a condition of accessing publications that users recognise and abide by the legal requirements associated with these rights.

Take down policy

If you believe that this document breaches copyright please contact us (research.lib@cbs.dk) providing details, and we will remove access to the work immediately and investigate your claim.
}

Download date: 26. Apr. 2023 
WP 2001-5

The Impact of Bankruptcy Rules on Risky Project Choice and Skill Formation under Credit Rationing

af

Shubhashis Gangopadhyay \& Clas Wihlborg

INSTITUT FOR FINANSIERING, Handelshøjskolen i København

Solbjerg Plads 3, 2000 Frederiksberg C

tlf.: 38153615 fax: 38153600

DEPARTMENT OF FINANCE, Copenhagen Business School

Solbjerg Plads 3, DK - 2000 Frederiksberg C, Denmark

Phone (+45)38153615, Fax (+45)38153600

www.cbs.dk/departments/finance

ISBN 87-90705-52-1

ISSN 0903-0352 


\title{
The Impact of Bankruptcy Rules on Risky Project Choice and Skill Formation under Credit Rationing
}

\author{
Shubhashis Gangopadhyay \\ Indian Statistical Institute, Delhi Centre and SERFA \\ New Delhi \\ India \\ E-mail:shubg@vsnl.com
}

and

Clas Wihlborg

Copenhagen Business School and University of Göteborg

Department of Finance

Solbjerg Plads 3

DK-2000 Fredriksberg

Denmark

E-mail:cw.fi@cbs.dk

First Version: December 1997; Present Version: August 2001

\begin{abstract}
:
The contribution of this paper is in emphasizing endogenous credit rationing in the analysis of effects of bankruptcy rules on entrepeneurs' decisions with respect to risktaking and ex ante skill-development. Unlike most of the literature, both the debt claim and the amount of debt financing is endogenous in our exercise. This allows us to determine the extent of credit rationing that banks use to tackle informational asymmetry. Credit rationing is non-trivial and increases the cost of capital when corporations are forced to access alternative sources of funding even when debt is a cheaper alternative. We thus solve for optimal debt-equity ratios in the capital structure of the corporation and entrepeneurs' risk-taking. Second, we allow entrepeneurs to invest in generating skill to handle risky projects. We show that bankruptcy policies are important determinants of all these outcomes in ways that in some cases contradict the existing literature, which does not consider endogenous credit rationing.
\end{abstract}




\section{The Impact of Bankruptcy Rules on Risky Project Choice and Skill Formation under Credit Rationing}

\section{Introduction}

The level of managerial skill is usually taken as given in analyses of entrepreneurs' project choices and banks' lending decisions, while banks' supply of debt is usually taken as given in analyses of risky project choice and managerial skill development. However, entrepreneurs' investment in managerial skill, their risk taking and the banks' willingness to finance risky projects are more likely to be endogenously determined. For example, if banks' willingness to finance risky projects increases, it becomes more profitable for managers to invest in the skills required to handle risky projects. On the other hand, when managers are more skilled, they may be more willing to take on risky projects. Knowing how managers and entrepreneurs behave, banks' willingness to lend, or the conditions under which banks lend, could change.

Bank willingness to lend to risky projects is expected to be affected to an important extent by the rules that govern the sharing of assets in situations of project failure, i.e., under bankruptcy. The contribution of this paper is in emphasizing endogenous credit rationing in the analysis of effects of bankruptcy rules on entrepreneurs' decisions. We explicitly investigate the effects on bank behavior, risky project choice, and managerial skill development of more or less strict bankruptcy rules. By strict rules we mean that absolute priority (APR) among creditors is upheld under limited liability of shareholders. 
There exists a large literature on the design and incentive effects of financial contracts. ${ }^{1}$ Standard debt contracts are efficient for project financing under a variety of circumstances including costly state verification and agency relations --- when outcomes or actions relating to the firm cannot be contractually controlled --- and adverse selection --- when characteristics of the firm cannot be identified. In this literature it is commonly assumed that there is a contractually specified absolute priority among creditors' claims in case of project failure. Under this assumption equity holders do not retain any claim on the assets if the debt cannot be serviced.

In this paper we assume that banks issue standard debt contracts under conditions of non-verifiability of projects' risk characteristics. We focus on the impact of deviations from APR on the ex ante incentives of banks and entrepreneurs who serve as project managers. Our paper makes two important additions to the literature on bankruptcy rules. One, unlike most of the literature, both the debt claim and the amount of debt financing -- and therefore also the interest rate on debt --- are endogenous in our exercise. Thereby, we are able to determine the extent of credit rationing that banks use to tackle the informational asymmetry. Credit rationing is non-trivial when firms are forced to access alternative sources of funding even when debt is a cheaper alternative. We thus solve for optimal debt-equity ratios in the capital structure of the firm. Second, we allow entrepreneurs to invest in generating skill to handle risky projects. We show that bankruptcy policies are important determinants of the supply of debt, risky project choice, and skill developments in ways that in some cases contradict the existing literature, which does not consider endogenous credit rationing.

\footnotetext{
${ }^{1}$ See Allen and Winton (1995) and-for a capital structure perspective-Harris and Raviv (1991)
} 
Bankruptcy institutions have become the focus of both research and policy debate in industrialized countries, as well as in emerging market economies. A large part of the economic research has focused on efficiency properties of bankruptcy law, including explicit procedures for restructuring that often allow deviations from absolute priority (APR) when insolvent firms' assets or their value are divided up in insolvency proceedings. One ex post efficiency issue is whether bankruptcy institutions induce restructuring rather than liquidation when it is economically efficient at the time of insolvency. White (1995) and Baird (1997) review this literature focusing on effects of Chapter 11 of the American bankruptcy code.

Limited liability has well-known consequences for excessive shareholder risktaking. ${ }^{2}$ Thus, strengthening shareholders' and managers' position in insolvency, as ex post violation of APR does, may affect efficiency thro ugh project choice, managerial skill development, as well as lending decisions. These consequences appear "ex ante" at the time investment and financing decisions are made.

Effects of bankruptcy procedures on managers' and entrepreneurs' ex ante incentives have been analyzed in a number of papers. ${ }^{3}$ For example, Bebchuk and Picker (1993) and Freirman and Viswanath (1994) make the case for deviations from APR on the grounds that (excessive) risk-taking is reduced when managers retain a stake in bankrupt firms' assets. Bebchuk and Picker, whose model in many ways is similar to ours, also argue that under-investment in specific managerial skill is reduced by deviations from APR. Berkovitch and Zender (1998) make a similar argument.

\footnotetext{
${ }^{2}$ See, for example, Rose-Ackerman (1991)

${ }^{3}$ See, for example, Gertner and Scharfstein (1991), Aghion and Bolton (1992), Bebchuk and Picker (1993), Freirman and Viswanath (1994), Bolton and Scharfstein (1996), and Berkovitch and Zender (1998).
} 
Another aspect of ex ante efficiency of bankruptcy rules is discussed in Cornelli and Felli (1997). They focus on the incentives of senior and junior creditors to monitor borrowers. Neither an APR-rule nor a more debtor friendly rule is ex ante efficient with respect to monitoring incentives for all creditors in their analysis. Monitoring incentives would presumably affect creditors' willingness to supply credit to particular projects as well. We assume that monitoring is insufficient to resolve the informational asymmetry between the entrepreneur and the creditor.

One strand, of the literature on bankruptcy institutions, focuses on bankruptcy costs and their role in the determination of capital structure (see Altman, 1984). This literature rarely addresses the issue of whether alternative rules affect the debt-equity structure of firms except through bankruptcy costs. We do not include explicit bankruptcy costs but assume that risky assets are firm-specific meaning that there is a dead-weight loss of asset value in case of bankruptcy.

We proceed by describing the model and its main attributes in Section 2 . The effects of more or less strict bankruptcy rules (deviations from APR) on risky project choice, the value of debt, and credit rationing, are analyzed und er the assumption that the entrepreneurs' skill levels are exogenous in Section 3. The skill levels of entrepreneurs are determined endogenously in Section 4. The effects of strictness of bankruptcy rules on risky project choice and skill levels are derived. Section 5 concludes. 


\section{The Model and its Attributes}

In this section we develop a model including an entrepreneur, a bank, and a large number of outside investors. Each entrepreneur has an identical safe project and the option of choosing a risky technology. All projects (both safe and risky) require investment $K$. The safe project gives a return $\mu$. The risky project gives a return $\mu+z$ with probability $\theta$, where $z>0$ captures managerial skill. With probability $1-\theta$ the project gives a return $\mu-b, \mu \geq b>0$, where $b$ captures deadweight losses when bankruptcy occurs.

There are four periods $0,1,2,3$. In period 0 all agents have symmetric information about what will happen in periods 1,2,3. Entrepreneurs invest in period 0 in skill development, which is specific to a particular kind of risky project and observable to financial market participants. The cost of generating this skill is $c(z)$. Entrepreneurs do not decide immediately on whether to invest in the risky project requiring the skill but they wait until a probability of success is privately revealed to them in period 1 . The skill provides the entrepreneur with an option to invest in the risky project if the probability of success is above a threshold. They may also decide to stay with the safe project. The entrepreneur is remunerated through an equity stake in the project.

In period 1, the capital structure of the project gets determined. The capital structure is defined by the breakup of debt and equity. The bank holds the debt claim $D$, while the equity owners are the entrepreneur (insider) and the small shareholders (outsiders). Let the investment (loan) by the bank be denoted $I, I \leq K$. The money put in by the equity holders is $K-I$. Let $r$ be the opportunity cost of funds to the bank and $q$ be the best alternative return to the small shareholders for their funds. Financial markets are imperfect in the sense that Modigliani-Miller conditions do not hold. In particular, the 
cost of equity $(q)$ exceeds the banks' opportunity cost of funds $(r)$, because, for example, issue costs of equity are higher than the costs to banks of issuing debt. Alternatively, the market for the firm's equity is not liquid or informative. Under these conditions the entrepreneur always prefers to borrow from a bank.

The choice of projects, safe or risky, is determined in period 2. In this period, the entrepreneur draws the probability of success on the risky project, $\theta$, from a distribution $F(\theta)$. The $\theta$ drawn by an entrepreneur is private information to the entrepreneur and is non-verifiable by the bank. Thus the bank and the entrepreneur cannot sign a contract that is conditional on the realized $\theta$. The choice between the safe and the risky project by the entrepreneur is obviously, conditional on $\theta$. The bank, on the other hand, has committed to provide debt financing before the project risk is fully revealed.

In period 3 the project realizations are obtained and the claims settled. If the safe project was chosen in period 2 , the project realization is $\mu$ in period 3. If the risky project was chosen, and it was successful, the realization is $\mu+z$; if unsuccessful, the return is $\mu-b$.

We give the following interpretation to the risky technology. Its outcome is dependent on two things --- the skill level $z$ which is specific to the risky technology, and $\theta$, which is the success probability attached to the risk undertaken by the entrepreneur. While there is a positive gain of $z$ should the project be a success, the cost of the risky technology is the loss in asset value, $b>0$, should the project be unsuccessful. In other words, the period 2 use of the specific skill by the entrepreneur reduces the future value of the asset. Successful completion of the project is sufficient to recover this asset degradation and improve on the total by $z$. The asset degradation in 
case of failure, $b$, is independent of the managerial skill, $z$. Therefore, managerial entrenchment is not present as it is in Bebchuk and Picker (1993), but our results are not substantially affected by this assumption as we will discuss later.

For efficiency, the choice of the project in period 2 must be such that the expected return is maximized. An entrepreneur, with specific skill $z$ who has drawn a particular $\theta$ will make an efficient choice of the risky project if she chooses the risky project only when

$$
\theta(\mu+z)+(1-\theta)(\mu-b) \geq \mu .
$$

The left hand side of the expression is the expected return on the risky project while the right hand side is the return on the safe project. Define

$$
\text { (1) } \quad \theta^{*} \equiv \frac{b}{b+z}
$$

At $\theta^{*}$, the last inequality holds as equality. Also, the inequality holds strictly for all $\theta>\theta^{*}$ and is violated for all $\theta<\theta^{*}$. Thus efficiency demands that risky projects be chosen for all $\theta \geq \theta^{*}$.

Throughout the paper, we will use the following assumptions:

A.1: $\quad c^{\prime}()>0,. c^{\prime \prime}()>$.0 for all $z>0$ and $c(0)=0$.

A.2: $\quad \mu \geq q K$

A.3: $\quad 0<b \leq \mu$.

A.4: $\quad q>r>0$.

A.5: $\theta$ is distributed between $[0,1]$ and $F(\theta)$ is twice differentiable for $\theta \in(0,1)$.

A.6: All agents are risk-neutral, while banks are competitive and give limited liability loans. The equity market is competitive. There is no strategic default by 
entrepreneurs.

A.1 postulates an increasing and convex cost function for the generation of specific skill. A.2 guarantees that entrepreneurs have economically viable projects. A.3 ensures that, given A.2 and equation (1), there will always be some threshold value of the probability of success on the risky projects, such that, all risky projects with a higher probability of success than this threshold are more profitable than the safe project. Alternatively, A.3 implies that $\theta^{*}$ is well defined. A.4 simply states that the equity cost of funds is higher than the bank's opportunity cost of funds, implying that debt is always a desirable source of funds. A.5 is a technical assumption implying a differentiable density function. Most known distribution functions will satisfy the assumption, including the uniform distribution. A.6 implies that banks do not earn excess profits, and that the supply of equity capital from outside shareholders is infinitely elastic at a price $q$. No strategic default implies that entrepreneurs pay their debt claims whenever they can.

\section{Model Results with Fixed Skill}

In this section we assume that the skill level, $z$, of the entrepreneur is given. We are, therefore looking at the problem from period 1 onwards. Later, we will investigate the choice of this skill, which is determined in period 0 .

The debt contract is signed in period 1 and settled in period 3. Let $D$ be the debt claim. The bank's payoff in period $3, \pi_{B}$, is a variable depending on the choice of the project and the realization on the risky project. Observe that, from A.6, default occurs only when project realizations are insufficient to meet the claim $D$. In a standard debt contract the bank will extract the full value of the realization, as long as the amount is 
less than $D$. This is usually effected through the transfer of ownership rights from the shareholders to the bank in the event of a default. This transfer occurs through the institutions governing bankruptcy procedures. If there are no transaction costs during this transfer of ownership, and/or the bankruptcy courts strictly adhere to the absolute priority rule (APR), we have the standard debt contract (Gale and Hellwig, 1985).

Suppose that $\mu>D>\mu-b$. If the safe project is chosen there is no default. If the risky project with probability $\theta$ is chosen, then with probability $(1-\theta)$ there will be default. In that case, given A.6, the bank should be able to realize $\mu-b$. Suppose instead, the bankruptcy institutions are costly and/or they do not strictly adhere to the APR. Then the bank, in the event of a default will get less than $\mu-b$. This can happen in two ways. First, since bankruptcy procedures are costly, the value left to be distributed between the bank and the shareholders, after the legal procedures, is only a fraction (less than one) of $(\mu-b)$. This could result from the fact that, $\mu-b$, the value of a failed risky venture, is verifiable by the bankruptcy institution only at a cost. Second, because the institutions may not adhere to the APR, the bank expects only a fraction of the true remaining value. In general, then the bank gets $x(\mu-b), 0 \leq x \leq 1$. The bank when evaluating the debt claim will take into account the nature of the bankruptcy institutions as they affect the payoffs in the event of a default.

For our purposes, however, we will consider deviations from APR as the primary reason for the bank getting less than the full liquidation value. Later, we will discuss what happens when bankruptcy institutions extract part of this value. In the event of default then, the shareholders obtain $(1-x)(\mu-b)$. Observe that, given that there is no strategic default, such considerations are irrelevant when $D \leq \mu-b$. 
An entrepreneur chooses projects depending on $\theta$. Since the bankruptcy

institutions need not enforce the APR, it is possible for the shareholders (including the entrepreneur) to extract a positive value even when there is a default. Let $\beta, \beta>0$, be the proportion of the project owned by the entrepreneur. If the risky project is chosen, and $\mu>D>\mu-b$, then, it must be the case that

$$
\begin{aligned}
& \beta[\theta(\mu+z-D)+(1-\theta)(1-x)(\mu-b)] \geq \beta(\mu-D) \\
& \Rightarrow \theta \geq \frac{\mu-D-(1-x)(\mu-b)}{\mu-D-(1-x)(\mu-b)+z}
\end{aligned}
$$

Let $\theta_{0}$ be the value of the success probability such that the entrepreneur is indifferent between her risky project and the safe project. Then, clearly, all risky projects with $\theta \geq \theta_{0}$, but with the same debt claim $D$, will be more profitable than the safe project. Those with $\theta<\theta_{0}$ will be less profitable than the safe project. In general,

$$
\theta_{0}= \begin{cases}0 & \text { if } \mu+z>D \geq \mu \\ \max \left[0, \frac{\mu-D-(1-x)(\mu-b)}{\mu-D-(1-x)(\mu-b)+z}\right] & \text { if } \mu>D>\mu-b \\ \theta^{*} & \text { if } \mu-b \geq D\end{cases}
$$

If $\mu+z>D \geq \mu$, the safe project gives a non-positive return, while the risky project gives a positive return with positive probability. This happens when the project is successful because $\mu+z$ is greater than $D$. If $D>\mu-b$, there is always a positive probability that a risky project may fail and, hence, we have to take into account the bankruptcy institutions.

The last line of (3) is the result of our assumption that there is no possibility of a strategic default on the safe project. In other words, suppose that the entrepreneur has opted for a safe project and, $\mu-D<(1-x)(\mu-b)$. Here the entrepreneur has an 
incentive to trigger a default even on the safe project. Without default, the shareholders get $\mu-D$. If, however, the entrepreneur defaults, and can hide the fact that a safe project was chosen, the shareholders will get $(1-x)(\mu-b)$. If $x$ is small, such a possibility is always there. In our model, we assume that such strategic defaults do not occur.

We can now write the period 1 expected value of a debt claim $D$. The entrepreneur draws her $\theta$ after the debt claim is determined and at a time when all agents have symmetric information on $F(\theta)$ but do not know which $\theta$ will be drawn. Also, since $\theta$ is either not observable by the bank, and/or unverifiable, the debt claim cannot be made contingent on $\theta$. The bank knows that for all $\theta<\theta_{0}$ the entrepreneur will stick to the safe project and, choose the risky project otherwise. To avoid having to use unnecessary algebra, we will assume that the bank never puts a debt claim that is more than what the risky entrepreneurs can pay even when they are successful, i.e., $D \leq \mu+z$. This is not a restrictive assumption if we believe that entrepreneurs will not start up projects unless they make positive profits. Any debt claim that takes away the entire return, even when projects are successful, will not encourage entrepreneurs to begin any project! It has the added perverse effect of making a failed project more profitable to the entrepreneur as with $x<1$, the entrepreneur can get a positive return on a failed project.

The expected payoff of the bank, $E \pi_{B}(D)$, given $D \leq \mu+z$ is:

(4) $E \pi_{B}(D)= \begin{cases}F\left(\theta_{0}\right) D+\int_{\theta_{0}}^{1}[\theta D+(1-\theta) x(\mu-b)] d F(\theta) & \text { if } D>\mu-b \\ D & \text { if } D \leq \mu-b\end{cases}$

Observe that, 
(5)

$$
E \pi_{B}(D)=D-[D-x(\mu-b)] \int_{\theta_{0}}^{1}(1-\theta) d F(\theta) \quad \text { if } \mu+z>D>\mu-b
$$

All entrepreneurs, who draw $\theta \geq \theta_{0}$, will choose the risky project and the rest, will stay with the safe project. The measure of firms choosing the safe project is $F\left(\theta_{0}\right)$ and that for risky project is $1-F\left(\theta_{0}\right)$. The bank's expected return is given by the integral in the first line of equation (4). If $D \leq \mu-b$ then the bank gets paid even when a risky project has failed and the second line of (4) gives its return.

Proposition 1: Let $z$ and $D$ be given. Under A.1-A.6, if $\mu+z>D>\mu-b$, then there is more than efficient risk-taking, i.e., $\theta_{0}<\theta^{*}$. Also, ceteris paribus, $\theta_{0}$ is decreasing in $D$, for $\theta_{0}>0$.

Proof: See Appendix.

This Proposition states that a debt contract, regardless of the strictness of the bankruptcy rule, introduces an inefficiency --- the measure of firms undertaking the risk, $1-F\left(\theta_{0}\right)$, is strictly greater than the optimal amount, $1-F\left(\theta^{*}\right)$, for a given skill level. It is important to note that this is happening because of limited liability and not because of the bankruptcy environment. From equation (3), if $D \leq \mu-b$, the choice of risky projects is efficient. For this range of values of the debt claim, there is no default, making limited liability irrelevant and, hence, produces no distortion in project choice. If $D>\mu-b$, there is positive probability of default on risky projects. Now, the presence of limited liability makes the entrepreneur's payoff convex and, hence, she prefers more risk 
at the margin. Shareholder value maximization is no longer the same as overall value maximization.

Note however that, under a positive probability of default, the extent of the inefficiency is determined by the strictness of the bankruptcy rule. Define the degree of inefficiency to be the gap between $\theta^{*}$ and $\theta_{0}$. If $\theta^{*}-\theta_{0}$ decreases, we say that the inefficiency has decreased.

Proposition 2: Let $z$ and $D$ be given. Under A.1-A.6, if $\mu+z>D>\mu-b$, the degree of inefficiency (as measured by $\theta^{*}-\theta_{0}$ ) falls as the strictness of the bankruptcy rule increases, i.e., as $x$ rises.

Proof: See Appendix.

Limited liability makes bank payoffs concave and more risk taking implies a lower expected return for them. On the other hand, from Proposition 2 it appears that, a tightening of the bankruptcy rules can mitigate the inefficiency in risk taking. This should have a positive effect on bank returns. Our next Proposition is a formal statement of this result.

Proposition 3: Let $z$ and $D$ be given. Under A.1-A.6, if $\mu+z>D>\mu-b$, the payoff to the bank increases as the strictness of the bankruptcy rule increases, i.e., as $x$ rises. Proof: See Appendix. 
Propositions 2 and 3 imply that a tightening of bankruptcy rules favors the bank. However, both these Propositions are true under a given debt claim. For a competitive bank, higher expected returns imply that its terms and conditions on the loans should change. This will translate into different levels of exposure by the banks and, in particular, $D$ can no longer be given if we change $x$. We will now study the effects of changing bankruptcy rules.

For non-trivial solutions that involve default possibilities, we will henceforth assume the following:

A.7: $E \pi_{B}(D)$ is strictly concave in $D$. Let $D^{*}$ maximize $E \pi_{B}(D)$ in (4). Then, $\mu>D^{*}>\mu-b$.

This assumption performs two functions. First, as stated earlier, it ensures that there is always a positive probability of default. Second, it ensures that the safe project is a valid alternative. If $D \geq \mu$, the safe project is never profitable. Note that A.7 does not guarantee that $\theta_{0}>0$. For that, we need $\mu-D-(1-x)(\mu-b)>0$, i.e., $D<x \mu+(1-x) b$.

Given A.6, the entire value of the project is divided up between the bank and the shareholders. Hence, the entrepreneur will want to pay the bank no more than what is necessary to make the bank invest. Given A.4, the entrepreneur will want the bank to invest as much as possible, before going to the equity market. For every $D$ the bank will invest $I$ such that $E \pi_{B}(D) \geq r I$. Given competitive banks and that firms want banks to invest as much as possible, the maximum amount of bank investment $I^{*}$ is obtained from (6) $\quad I^{*}=\min \left\{K, \frac{E \pi_{B}\left(D^{*}\right)}{r}\right\}$ 
Observe that, $r I$ is the opportunity cost of the bank if it lends $I$. Recall that $K$ was the funding required for projects to get started. If $E \pi_{B}(D) / r$ is no less than $K$, then the bank lends $K$ and, the equity market is never tapped by the entrepreneur since $q>r$. This makes the equity market irrelevant. To get non-trivial results, one must consider cases where the entrepreneurs access both the debt and equity markets. Entrepreneurs will access the equity market if

A.8: $\quad I^{*}<K$.

Under A.8, the firm is not fully financed by the bank. Here, credit rationing of individual projects is the result of the aggregate composition of risky to safe projects. If banks could monitor the choice of projects, they could have announced a debt claim of $r K$ against an investment of $K$ for at least those choosing the safe project. This would have been efficient given A.2 and A.4. Indeed, in our model, optimality demands that all project funding comes from the bank. However, private information on risky projects encourages too much risk-taking behavior by entrepreneurs. The bank resorts to creditrationing to counter this.

In certain ways, this sort of credit rationing is similar to that in Moore (1993). In Moore, borrowers are capable of strategic default, since actual realization is private information to borrowers. This requires lenders to commit to a verification cost whenever borrowers default. This, in turn, increases the expected monitoring costs from a higher bank investment as the probability that returns are lower than the debt claim increases with higher debt claims. There is, therefore, an optimal debt claim and associated with that, an optimal amount of bank financing of projects. The logic of our argument is similar to that of Moore, though the structure is different. The advantage of 
the approach of Moore and that taken by us, is the endogenous choice of the debt claim and, hence, the capital structure of the firm.

A.8 has another important role in our model. After our first Proposition, we argued that without a positive probability of default, there is no effect of limited liability on the efficient choice of risk. A.4 implies that tapping the equity market is not efficient. If A.8 does not hold, then the project is completely debt financed. The role of equity markets then becomes irrelevant to our analysis. The inefficiency, if any, is the result of limited liability only. With A.8, there is an additional distortion due to credit rationing and the consequent fact that entrepreneurs have to access the more costly equity market. Indeed, from Proposition 3 it follows that the possibility of credit rationing increases as the bankruptcy rule becomes less strict. This is immediate from the fact that $E \pi_{B}$, and hence $\left(E \pi_{B} / r\right)$, falls as $x$ decreases.

If A.8 holds, the project needs an additional amount $K-I$. The entrepreneur gets this from the equity market. If the entrepreneur keeps $\beta$ proportion of the project for herself, the ownership of the outside shareholders, $(1-\beta)$, must be such that the outsiders are willing to invest. In other words, if $E \pi_{S}$ is the expected value to the outside shareholders, we must have

$$
(1-\beta) E \pi_{S} \geq q(K-I)
$$

where,

$$
{ }^{E \pi_{S}}=(\mu-D) F\left(\theta_{0}\right)+\int_{\theta_{0}}^{1}[\theta(\mu+z-D)+(1-\theta)(1-x)(\mu-b)] d F(\theta) \text { if } \mu>D>\mu-b
$$


For all entrepreneurs choosing the safe project, the return to equity is $\mu-D$, and this will happen with probability $F\left(\theta_{0}\right)$. This gives us the first term in the second line of (8). For $\theta \geq \theta_{0}$, the entrepreneurs will choose the risky project. If successful, the equity holders will get $\mu+z-D$; if unsuccessful, they will get $(1-x)(\mu-b)$. These two returns will have to be weighted by their probabilities, for all entrepreneurs who draw a probability of success greater than, or equal to, $\theta_{0}$. This gives us the integral in (8). Equation (8) can be rewritten as

(9) $E \pi_{S}=\mu F\left(\theta_{0}\right)+\int_{\theta_{0}}^{1}[\theta(\mu+z)+(1-\theta)(\mu-b)] d F(\theta)-E \pi_{B}(D)$

The value of the firm $V$ is the sum of $E \pi_{B}+E \pi_{S}$. Thus,

$$
V=\mu F\left(\theta_{0}\right)+\int_{\theta_{0}}^{1}[\theta(\mu+z)+(1-\theta)(\mu-b)] d F(\theta)
$$

A.6 guarantees that (7) will hold with equality, while A.2 and A.4 guarantee that $\beta>0$, as long as there is a positive amount of investment by the bank. Observe that, the value of the firm changes only when $\theta_{0}$ changes, when the value of $z$ is given.

Proposition 4: Let $z$ be given. Under A.1-A.7, if $\theta_{0}=0$, then there is no credit rationing.

Proof: See Appendix.

An increase in the debt claim increases the bank's payoff if the composition of project choice does not change. From Proposition 1 we know that, for $\theta_{0}>0$, an increase 
in the debt claim encourages some safe entrepreneurs to choose risky projects. This has a negative effect on bank returns as the aggregate default probability now increases and because there is limited liability. However, if $\theta_{0}$ is already at its lowest possible value, then an increased debt claim cannot change the aggregate composition of projects. Hence there is no negative effect from an increased debt claim on bank returns. The bank can, therefore, increase its debt claim. However, for competitive banks, an increased debt claim will have to be matched by an increased investment on the project, to ensure zero profit. What prevents the bank from increasing the debt claim must come from its inability to increase investment. This can happen only if investment is already at $K$, implying there is no credit rationing. This Proposition implies that credit rationing is always associated with $\theta_{0}>0$. It is possible, however, that there is no credit rationing and $\theta_{0}>0$. For the rest of the paper, we will consider the case when A.8 holds, i.e., there is credit rationing.

Proposition 5: Under A.1-A.8 and a given $z$, risk taking, i.e., the value of $\theta_{0}$, is independent of (small) changes in $x$, the degree of deviation from APR. Proof: See Appendix.

An increase in $x$ implies a closer adherence to the APR. It also means that, ceteris paribus, $E \pi_{B}$ increases for a given level of $D$. As the steps in the proof of Proposition 5 show, a higher $x$ increases the maximizing value of the bank's debt claim $D$. While the direct effect of $x$ is to increase $\theta_{0}$, the indirect effect, through an increased $D$ is to reduce it. Proposition 5 argues that the two effects cancel out each 
other in our model. This result is entirely different from the situation when $D$ is given. In Proposition 2 we had argued that if $D$, the bank's debt claim, is fixed, then excessive risk taking is reduced as the strictness of the bankruptcy rule increases. In both cases, if there is credit rationing, banks will optimally respond to improved creditor friendly bankruptcy rules by releasing more credit.

Bebchuk and Picker (1993) and Freirman and Viswanath (1994) argue in favor of a weakening of APRs in bankruptcy courts on the grounds that the over-investment in risky projects caused by limited liability would be reduced. In both papers the debt claim is fixed. Propositions 2 and 3 above based on the same assumption say that strict enforcement of APR reduces the over-investment in risky projects. Bebchuk and Picker's result is explained by reduced managerial entrenchment through risky investments when management retains a share in a bankrupt firm's assets. We have excluded managerial entrenchment by assuming that the loss of value of risky assets in bankruptcy, $b$, is independent of the return to investment in skills required by risky projects, $z$. Freirman and Viswanath's result is explained by risk averse managers' sharing of the downside risk when there are deviations from APR. Proposition 5 above, stating that risk-taking is independent of deviations from APR when the debt claim is endogenous, implies that the effects on risk-taking incentives of deviations from APR are offset by the banks' rationing of debt to managers with strong incentives to take risk. This result is not affected by the assumption that there is no managerial entrenchment, i.e. that $b$ is independent of $z$. 
Proposition 6: Under A.1-A.8 and a given $z, I^{*}$ increases for small increases in $x$, i.e., the extent of credit rationing is reduced when bankruptcy rules favors the bank more than the firm.

Proof: See Appendix.

Equation (10) gives us the ex ante value of the firm. Observe that it is completely determined by the value of $\theta_{0}$, the threshold value of success probability beyond which entrepreneurs implement risky projects. Proposition 5 argues that this threshold probability is independent of changes in $x$, the strictness with which the APR is implemented. Thus, the value of the firm remains unchanged as we change the strictness of the bankruptcy rules.

However, the varying degree of enforcement of the APR, changes the debt equity mix of the project. From our discussions we know that as $x$ increases, the expected value of debt increases, i.e., $E \pi_{B}($.$) goes up with x$ (see the steps in the proof of Proposition 6). Since the value of the firm stays the same (from Proposition 5 and equation (10)), the debt equity ratio (at market values) increases with $x$. According to the Modigliani-Miller theorem, the value of the firm is independent of the debt equity mix of the project. An important assumption there was that of perfect capital markets. With credit rationing, and $q>r$, we do not have perfect capital markets and, yet, the value of the firm is invariant to different debt-equity mixes triggered by the differing values of $x$. This is happening simply because in our model, the bank is free to choose both the debt claim and the amount of investment, as long as it ensures zero profit for itself. This reduces the need for outside equity as the bank increases its investment. Consequently, the manager's share in 
the firm, $\beta$, increases. With risk neutral agents, this implies that the enforcement pattern of the APR affects the distribution of surplus among the investors, but not the total surplus to be distributed.

So far we have assumed that the skill level of managers is given. In the next section we will allow the skill level to be chosen by managers. We will show that a change in the value of $x$, or the strictness of the APR, has serious consequences for the levels of human capital, or skill, generated by managers.

Before finishing this section, we consider the ex ante effects of bankruptcy costs. So far we have been assuming that, in the event of default, the amount to be shared between the bank and the shareholders is $\mu-b$. If we introduce bankruptcy costs as a deadweight loss, $\alpha$, then the amount to be shared between the bank and shareholders is $\mu-b-\alpha, 0<\alpha \leq \mu-b$. As the bankruptcy cost increases, both the bank and the shareholders lose. This implies that $\theta_{0}$ unambiguously goes up with the introduction of $\alpha$.

We interpret $\alpha$ as a transaction cost brought about by the bankruptcy institution. This cost does not affect the value of efficient risk-taking, which continues to be defined by equation (1). In this case the gap between $\theta^{*}$ and $\theta_{0}$ decreases with $\alpha$. The degree of excess risk-taking measured by $\theta^{*}-\theta_{0}$ is reduced. Ceteris paribus, an increase in $\alpha$ reduces the value of a risky project to both creditors and shareholders. The decline in the value from the entrepeneur's point of view reduces incentives for risk-taking. As a consequence of this effect in isolation, the bank is willing to supply more debt and risktaking increases again. However, the bankruptcy cost reduces the value of the project to 
the bank as well, and this effect reduces the supply of debt. The net effect is a reduction in risk-taking.

\section{Endogenous Skill}

So far, we have taken the skill decisions in period 0 as given. We now solve for the optimal choice of skill as a function of the bankruptcy environment using the results derived above. Rewriting (7) as an equality, and recalling that the entrepreneur owns a proportion $\beta$ of the project, the return to the entrepreneur, $\beta E \pi_{S}$, is equal to $E \pi_{S}-q(K-I)$. We have also defined the value of the firm, $V$, as $E \pi_{B}+E \pi_{S}$. We can write

$$
\beta E \pi_{S}=V-E \pi_{B}-q(K-I)
$$

The period 0 expected return of the entrepreneur, $W$, is

$$
W=\beta E \pi_{S}-c(z)=V-E \pi_{B}-q(K-I)-c(z)
$$

Using $E \pi_{B}\left(D^{*}\right)=r I^{*}$, we can write

$$
W=V-q K+(q-r) I^{*}-c(z)
$$

The following proposition is derived for the effect of closer adherence to APR on skill development in period 0 :

Proposition 7: Under A.1 to A.8, entrepreneurial skill increases as the bankruptcy rule approaches APR i.e. as $x$ increases.

Proof: From Proposition 5, $\theta_{0}$ is invariant to changes in $x$. Hence, it is immediate from (10) that there is no change in the value of the firm, $V$. From (19), we have 
(20) $\frac{\delta W}{\delta x}=\frac{\delta}{\delta x}\left[V-q K+(q-r) I^{*}\right]=(q-r) \frac{\delta I^{*}}{\delta x}$

which is positive from Proposition 6 and A.4. From A.1, it now follows that $z$ must increase with $x$. ।

As $x$ increases, the amount of bank investment increases. This reduces the amount of outside equity investment, which is a more costly source compared to the bank. The project, therefore, saves an amount $(q-r)$ for each unit of equity investment substituted for by bank credit. Since the market for outside equity is competitive, the entrepreneur extracts the entire additional value. This increases the return to managerial skill and, hence, encourages a greater investment in $z$.

The result in Proposition 7 is in contradiction to, for example, Bebchuk and Picker (1993) and Berkovitch and Zender (1998), who argue that increased deviations from APR help induce managers and entrepreneurs to commit resources ex ante. There are two important properties in our model that causes this difference --- $q>r$ (A.4), and the fact that we allow for the endogenous determination of bank investment and debt claims. The other models share neither of these two properties. First observe that with $q=r, \frac{\delta W}{\delta x}=0$ (equation (20)) and there is no effect on skill generation. Thus one does not obtain the results of Bebchuk-Picker and Berkovitch-Zender, if the capital structure of projects is endogenously determined in a credit rationed world. Second, the capital market imperfection of $q>r$ makes it all the more important for economic efficiency to have strict adherence to APR. 


\section{Conclusions}

We have developed a model of an entrepreneur's choice of risk-taking and managerial skill development in a model with endogenous credit rationing, caused by the bank's inability to observe or to verify the entrepreneur's risk-taking behavior after the loan has been granted. The only signal banks obtain, before loan decisions are made, about managers' inclination to invest in risky projects is managers' investments in skill development, which is required for risky projects.

The result with respect to bankruptcy institutions and managerial skill development is that closer adherence to absolute priority (APR) tends to increase skill development, because credit rationing will be reduced for any level of skill. With respect to average risk-taking as reflected in the minimum probability of success inducing entrepreneurs to choose risky projects over safe ones, we find that risk-taking tends to be independent of deviations from APR. The reason is that closer adherence to APR on the one hand reduces incentives for risk-taking but, on the other hand, reduced credit rationing offsets this incentive-effect. One common argument in favor of deviations from APR in the form of Chapter 11- type bankruptcy rules has been that such rules would enhance managers' incentives to invest in firm-specific skills. It has also been argued that deviations from APR can reduce incentives for excessive risk-taking. Our results show that these incentive-based arguments do not hold if there is credit rationing.

Weak bankruptcy institutions characterize most emerging economies and many of them are trying to institute reforms of bankruptcy rules. An important element of financially reforming economies is the underdeveloped equity, or stock, market and, thus, 
equity is, in general, more costly than bank debt. This paper suggests that such markets need to have strict adherence to APR if they want efficient investment and growth of entrepreneurial skill.

Another implication of our analysis is that, if there is credit rationing, the capital structures of projects should be closely related to the strictness with which the bankruptcy institutions adhere to the APR. Credit rationing is, theoretically, a well-established outcome in markets characterized by limited liability and asymmetric information (Stiglitz and Weiss, 1981; Moore, 1993). According to our model credit rationing will be more pronounced in economies with weak bankruptcy laws. Empirically, this should show up as lower debt equity ratios in economies with weak enforcement of bankruptcy rules, compared to those economies where there is strict adherence to bankruptcy procedures. ${ }^{4}$

\footnotetext{
${ }^{4}$ This argument presumes that banks in countries with different bankruptcy rules are not implicitly or explicitly protected against consequences of credit losses. It seems, however, that many countries with relatively debtor friendly bankruptcy rules also have banking systems that enforce debt contracts relatively weakly. See Wihlborg and Gangopadhyay (2001).
} 


\section{References}

Aghion, Philippe and Patrick Bolton (1992), "An Incomplete Contracts Approach to Financial Contracting," Review of Economic Studies, 59(3), 473-94.

Allen, Franklin, and Andrew Winton (1995), "Corporate Financial Structure, Incentives and Optimal Contracting", in Jarrow, R. et al (eds) Handbook in Operations Research and Management Science, Elsevier Science B.V., Amsterdam

Altman, Edward (1984), “A Further Empirical Investigation of The Bankruptcy Cost Question” Journal of Finance, (Sept.), 1067-1085.

Baird, Douglas G. (1997), "The Hidden Virtues of Chapter 11," Chicago Law and Economics Working Paper No. 43.

Bebchuck, L.A., and R.C. Picker (1993), "Bankruptcy Rules, Managerial Entrenchment, and Firm Specific Human Capital," Chicago Law and Economics Working Paper No. 16.

Berkovitch, E. R. I. and J.F. Zender (1998), "The Design of Bankruptcy law: A Case for Management Bias in Bankruptcy Reorganizations", Journal of Financial and Quantitative Analysis, 33 (4), December, 441-64

Bolton, Patrick and David S. Scharfstein (1996), "Optimal Debt Structure and the Number of Creditors," Journal of Political Economy, 104(1), 1-25.

Cornelli, Francesca and Leonardo Felli (1997), "Ex-ante Efficiency of Bankruptcy Procedures," European Economic Review, 41, 475-85.

Frierman, Michael and P. V. Viswanath (1994), "Agency Problems of Debt, Convertible Securities, and Deviations from Absolute Priority in Bankruptcy," The Journal of Law and Economics, 37(2)

Gale, Douglas and M. Hellwig (1985), "Incentive Compatible Debt Contracts: The OnePeriod Problem," Review of Economic Studies, 52, 647-63.

Gertner, R. and D. Scharfstein (1991), "A Theory of Workouts and the Effects of Reorganization Law, Journal of Financial Economics, 46 (4), 1189- .

Harris, M. and A. Raviv (1991), "The Theory of Capital Structure”, Journal of Finance, 46 (2), 297-335.

Moore, Robert R. (1993), "Asymmetric Information, Repeated Lending and Capital Structure," Journal of Money Credit and Banking, 25(3), 393-409.

Rose-Ackerman, S.(1991), "Risk-taking and Ruin: Bankruptcy and Investment Choice", Journal of Legal Studies, (June) 277-310 
Stiglitz, Joseph and Andrew Weiss (1981), "Credit Rationing in Markets with Imperfect Information”, American Economic Review, 71(3), 393-410.

White, Michelle J. (1995), “The Costs of Corporate Bankruptcy: A US-European Comparison," in Jagdeep S. Bhandari (ed.) Bankruptcy: Economic and Legal Perspectives.

Wihlborg, Clas, and Shubhashis Gangopadhyay (2001), "Infrastructure Requirements in The Area of Bankruptcy Law", Brookings-Wharton Papers on Financial Services, Forthcoming 


\section{APPENDIX}

Proposition 1: Let $z$ and $D$ be given. Under A.1-A.6, if $\mu+z>D>\mu-b$, then there is more than efficient risk-taking, i.e., $\theta_{0}<\theta^{*}$. Also, ceteris paribus, $\theta_{0}$ is decreasing in $D$, for $\theta_{0}>0$.

Proof: In section 2 we had argued that efficiency demands that an entrepreneur chooses the risky project only if $\theta$ is no less than $b /(b+z) \equiv \theta^{*}$. However, if $\theta_{0}<\theta^{*}$, then the measure of $\theta$ over which the risky project is chosen increases. Define $A \equiv[\mu-D-(1-x)(\mu-b)]$

Then, we can write $\theta_{0}$ as $A /(A+z)$. So, $\theta_{0}<\theta^{*}$ if and only if $A /(A+z)<b /(b+z)$, which is equivalent to $D>x(\mu-b)$. This is guaranteed by A.7, since $0 \leq x \leq 1$. The second part is immediate from differentiating $A /(A+z)$ with respect to $D$, keeping in mind that $\theta_{0} \geq 0$. I

Proposition 2: Let $z$ and $D$ be given. Under A.1-A.6, if $\mu+z>D>\mu-b$, the degree of inefficiency (as measured by $\theta^{*}-\theta_{0}$ ) falls as the strictness of the bankruptcy rule increases, i.e., as $x$ rises.

Proof: Observe that $\theta^{*}$ is independent of $x$. Hence, it is sufficient to check the movement of $\theta_{0}$.

$\frac{\delta \theta_{0}}{\delta x}=\frac{\delta}{\delta x}\left(\frac{A}{A+z}\right)=\frac{z(\mu-b)}{(A+z)^{2}}>0$. We, therefore, have $\frac{\delta}{\delta x}\left(\theta^{*}-\theta_{0}\right)<0$ and this proves our result. $\quad$ i 
Proposition 3: Let $z$ and $D$ be given. Under A.1-A.6, if $\mu+z>D>\mu-b$, the payoff to the bank increases as the strictness of the bankruptcy rule increases, i.e., as $x$ rises.

Proof: For this we need to check the sign of $\frac{\delta E \pi_{B}}{\delta x}$ for given values of $D$. From equation (5) in the text,

$$
\frac{\delta E \pi_{B}}{\delta x}=(\mu-b) \int_{\theta_{0}}^{1}\left(1-\theta_{0}\right) d F(\theta)+[D-x(\mu-b)]\left(1-\theta_{0}\right) f\left(\theta_{0}\right) \frac{\delta \theta_{0}}{\delta x},
$$

which is positive, given $\frac{\delta \theta_{0}}{\delta x}>0$ from Proposition 2.

Proposition 4: Let $z$ be given. Under A.1-A.7, if $\theta_{0}=0$, then there is no credit rationing.

Proof: $\theta_{0}=0$ implies that $\mu-D-(1-x)(\mu-b)=x \mu+(1-x) b-D \leq 0$. Also, $\theta_{0}=0$, implies from equation (5) in the text,

$\left.\frac{\delta E \pi_{B}}{\delta D}\right|_{\theta_{0}=0}=1-(1-E \theta)>0$. The bank can increase its debt claim and improve its expected payoff. However, since banks are competitive, this will automatically require a higher investment by the bank. Thus, the only reason for the bank to continue with this $D$ is that it cannot increase its investment on the project. This will happen only if $I^{*}=K$ 
Proposition 5: Under A.1-A.8 and a given $z$, risk taking, i.e., the value of $\theta_{0}$, is independent of (small) changes in $x$, the degree of deviation from APR.

Proof: Differentiating $E \pi_{B}(D)$ with respect to $D$, we get

$$
\begin{aligned}
& \frac{\delta E \pi_{B}(D)}{\delta D} \\
= & 1-\int_{\theta_{0}}^{1}(1-\theta) d F(\theta)+[D-x(\mu-b)]\left(1-\theta_{0}\right) f\left(\theta_{0}\right) \frac{\delta \theta_{0}}{\delta D}
\end{aligned}
$$

Define $N \equiv \frac{\delta E \pi_{B}(D)}{\delta D}$. Our assumptions guarantee that, at $D^{*}, N=0$, while strict concavity implies that $\frac{\delta^{2} E \pi_{B}(D)}{\delta D^{2}} \equiv \frac{\delta N}{\delta D}<0$. Setting $N \equiv 0$ and totally differentiating,

$$
0=\left.\frac{\delta N}{\delta D}\right|_{(\delta x=0)} \delta D+\left.\frac{\delta N}{\delta x}\right|_{(\delta D=0)} \delta x
$$

From equation (3), given A.7, we have

(12) $\left.\frac{\delta \theta_{0}}{\delta x}\right|_{(\delta D=0)}=\frac{z}{(A+z)^{2}}(\mu-b)=\left(-\left.\frac{\delta \theta_{0}}{\delta D}\right|_{(\delta x=0)}\right)(\mu-b)$

where $A \equiv \mu-D-(1-x)(\mu-b)$. For ease in notation, write $N=1-N_{1}+N_{2}$, where

$N_{1}=\int_{\theta_{0}}^{1}(1-\theta) d F(\theta)$ and $N_{2}=[D-x(\mu-b)]\left(1-\theta_{0}\right) f\left(\theta_{0}\right) \frac{\delta \theta_{0}}{\delta D}$. From $(10)$,

$$
\left.\frac{\delta N}{\delta D}\right|_{(\delta x=0)}=\left(1-\theta_{0}\right) f\left(\theta_{0}\right) \frac{\delta \theta_{0}}{\delta D}-\left.\left(\frac{\delta}{\delta \theta_{0}}\left[N_{1}-N_{2}\right]\right) \frac{\delta \theta_{0}}{\delta D}\right|_{(\delta x=0)},
$$

and

$$
\left.\frac{\delta N}{\delta x}\right|_{(\delta D=0)}=-(\mu-b)\left(1-\theta_{0}\right) f\left(\theta_{0}\right) \frac{\delta \theta_{0}}{\delta D}-\left.\left(\frac{\delta}{\delta \theta_{0}}\left[N_{1}-N_{2}\right]\right) \frac{\delta \theta_{0}}{\delta x}\right|_{(\delta D=0)} .
$$

Observe that using (12) and (13) in (14), we get, 
(15) $\frac{\delta N}{\delta x}=-(\mu-b) \frac{\delta N}{\delta D}$

Substituting (15) into (11), we have

(15) $\frac{\delta D}{\delta x}=\mu-b>0$

The total change in $\theta_{0}$ is through the direct effect of $x$ and the indirect effect through

$D$. Thus,

$\frac{d \theta_{0}}{d x}=\frac{\delta \theta_{0}}{\delta x}+\frac{\delta \theta_{0}}{\delta D} \frac{\delta D}{\delta x}=0$

from (12) and (15). i

Proposition 6: Under A.1-A.8 and a given $z, I^{*}$ increases for small increases in $x$, i.e., the extent of credit rationing is reduced when bankruptcy rules favors the bank more than the firm.

Proof: From Proposition 2, we know that $\theta_{0}$ does not change with increases in $x$. Using the definition of $E \pi_{B}(D)$ from (4) and A.7,

(16) $\frac{d E \pi_{B}(D)}{d x}=\frac{\delta E \pi_{B}(D)}{\delta x}+\frac{\delta E \pi_{B}(D)}{\delta D} \frac{\delta D}{\delta x}$

Recall that (16) has to be evaluated a $D=D^{*}$, at which value of $D$ the bank's revenue is maximized. From (4) and A.7, this implies that $\frac{\delta E \pi_{B}\left(D^{*}\right)}{\delta D}=0$. Again, from (4) and A.7, $\frac{\delta E \pi_{B}\left(D^{*}\right)}{\delta x}>0$. This proves the result, given (6) and A.8. 